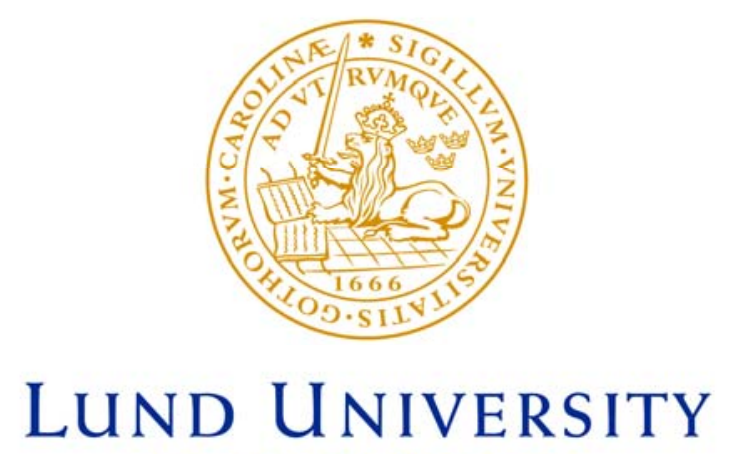

Faculty of Medicine

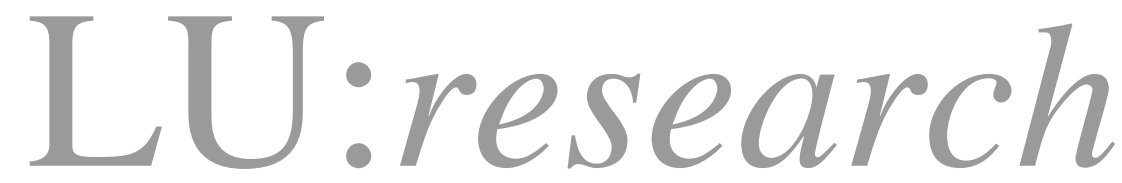

Institutional Repository of Lund University

This is an author produced version of a paper published in The international journal of biochemistry \& cell biology. This paper has been peer-reviewed but does not include the final publisher proof-corrections or journal pagination.

Citation for the published paper:

Davies, Julia R and Kirkham, Sara and Svitacheva, Naila and Thornton, David J and Carlstedt, Ingemar.

"MUC16 is produced in tracheal surface epithelium and submucosal glands and is present in secretions from normal human airway and cultured bronchial epithelial cells"

The international journal of biochemistry \& cell biology, 2007, Vol: 39, Issue: 10, pp. 1943-54.

http://dx.doi.org/10.1016/j.biocel.2007.05.013

Access to the published version may require journal subscription.

Published with permission from: Elsevier 


\title{
MUC16 is produced in tracheal surface epithelium and submucosal glands and is present in secretions from normal human airway and cultured bronchial epithelial cells
}

\author{
${ }^{1,2}$ Julia R. Davies $\ddagger$, ${ }^{3}$ Sara Kirkham, ${ }^{1}$ Naila Svitacheva, ${ }^{3}$ David J. Thornton and ${ }^{1}$ Ingemar \\ Carlstedt
}

${ }^{1}$ Mucosal Biology Group, Department of Experimental Medical Science, Lund University, BMC, C13, S-221 84, Lund, SWEDEN, ²Department of Oral Biology, Faculty of Odontology, Malmö University, S-20506, Malmö, SWEDEN, ${ }^{3}$ Faculty of Life Sciences, University of Manchester, Manchester M13 9PT, UK

Running Title: Human airway MUC16

\section{Corresponding Author:}

Dr Julia Davies

Department of Oral Biology, Faculty of Odontology, Malmö University, S-20506, Malmö, SWEDEN

Email: Julia.Davies@od.mah.se Tel: + 46406658492

Fax: +46 406658494 


\section{ABSTRACT}

The gel-forming MUC5AC and MUC5B mucins have been identified as major components of human airway mucus but it is not known whether additional mucin species, possibly with other functions, are also present. MUC16 mucin is a well known serum marker for ovarian cancer, but the molecule has also been found on the ocular surface and in cervical secretions suggesting that it may play a role on the normal mucosal surface. In this investigation, the LUM16-2 antiserum (raised against a sequence in the N-terminal repeat domain) recognized MUC16 in goblet and submucosal gland mucous cells as well as on the epithelial surface of human tracheal tissue suggesting that the mucin originates from secretory cells. MUC16 mucin was present in 'normal' respiratory tract mucus as well as in secretions from normal human bronchial epithelial (NHBE) cells. MUC16 from NHBE cells was a high-molecularmass, monomeric mucin which gave rise to large glycopeptides after proteolysis. N- and Cterminal fragments of the molecule were separated on gel electrophoresis showing that the MUC16 apoprotein undergoes a cleavage between these domains, possibly in the SEAdomain as demonstrated for other transmembrane mucins; MUC1 and MUC3. After metabolic labeling of NHBE cells, most of the secreted monomeric, high-molecular-mass $\left[{ }^{35} \mathrm{~S}\right]$ sulphate-labelled molecules were immunoprecipitated with the OC125 antibody indicating that MUC16 is the major [ $\left.{ }^{35} \mathrm{~S}\right]$ sulphate-labelled mucin in NHBE cell secretions.

Key Words: Cell-associated mucin, mucus, gel-forming mucin, airway, air-liquid interface, primary culture 


\section{INTRODUCTION}

The CA 125 antigen, which was first detected by Bast et al. in 1981 using the OC125 monoclonal antibody, provides the basis for assays to detect and monitor the progression of epithelial ovarian cancer. The antigen is now known to be carried by a large mucin-like molecule encoded by the MUC16 gene (Yin \& Lloyd, 2001; Yin, Dnistrian \& Lloyd, 2002). The MUC16 apoprotein is predicted to be very large, with three major domains: a glycosylated N-terminal domain of approximately 1600 amino acids, a large glycosylated repeat domain containing around 60 repeats of a 156 amino acid sequence and a C-terminal domain (O’Brien et al., 2001; Yin \& Lloyd, 2001). Since the publication of the original sequence data, O’Brien et al. have described an extension to the N-terminal domain which would extend the molecule by a further 10,431 amino acids (O’Brien, Beard, Underwood, \& Shigemasa, 2002). The predicted C-terminal of ovarian MUC16 includes a transmembrane sequence suggesting that, in this tissue, the molecule is tethered in the cell membrane. The presence of a SEA module is a characteristic feature of cell-associated mucins, but MUC16 differs from the others in that six such modules are present; the most C-terminal being located between the repeat and the transmembrane domains (O’Brien et al., 2001). While the GSVVV motif, identified as a site of cleavage in MUC1, MUC3 and MUC12 (Khatri, Wang, \& Forstner, 2003; Palmai-Pallag et al., 2005; Parry et al., 2001) is not present in MUC16, the most C-terminal SEA domain contains a related sequence although it has not been shown that the apoprotein undergoes cleavage in this region.

Due to its use as an ovarian tumour marker, much of the work carried out to date on CA125/MUC16 has focused on its potential involvement in the development and progression of cancer. However, MUC16 has also been detected in cervical mucus (Nustad et al., 2002) and corneal epithelial cells (Argueso, Spurr-Michaud, Russo, Tisdale, \& Gipson, 2003), suggesting that it may be a component of normal mucosal secretions at some sites. In the 
airway, large oligomeric mucins: MUC5AC derived mainly from the goblet cells (Hovenberg, Davies, \& Carlstedt, 1996) and MUC5B originating largely from the submucosal gland mucous cells (Wickström, Davies, Eriksen, Veermann, \& Carlstedt, 1998) have been identified as the major components of the mucus gel network. However in our studies, where airway tissue was metabolically labelled with ${ }^{35} \mathrm{~S}$-sulphate or ${ }^{3} \mathrm{H}$-monosaccharides, radiolabelled “mucin-like” molecules were also present in secretions (Somerville et al., 1992; Svitacheva, Hovenberg, \& Davies 1998; Svitacheva, \& Davies, 2001). The size and monomeric nature of these molecules is compatible with that of cell-associated mucins, for instance, MUC16 and MUC4. (Svitacheva, Hovenberg, \& Davies, 1998). Although found in baseline secretions, release of mucin-like molecules from human and feline airways was increased in response to bacterial exoproducts such as mono-rhamnolipid from the airway pathogen Pseudomonas aeruginosa (Somerville et al., 1992) suggesting that these molecules play an important role in airway mucosal responses to bacteria.

The aim of this investigation was to determine whether, and if so where, MUC16 is produced in human airways. Since previous studies have suggested that mucin-like molecules may be important in mucosal responses to bacteria (Somerville et al., 1992), we also set out to determine whether such components could correspond to MUC16. Aberrant glycosylation is a common feature of carcinoma-associated mucins and antibodies raised against tumourderived molecules may thus recognize epitopes which are masked, or are not present in their “normal” counterparts. To avoid such potential problems, a novel MUC16 peptide antibody (LUM16-2) recognizing a sequence in the N-terminal domain, predicted to be largely unglycosylated, was developed and used in this study. As a tool to study whether cleavage analogous to that in other cell-associated mucins e.g. MUC1 occurs in MUC16, a second peptide antibody (LUM16-4), recognizing the C-terminal domain of the molecule, was also developed. 


\section{MATERIALS AND METHODS}

\section{Materials and analytical methods}

CHAPS and guanidinium chloride $(\mathrm{GdmCl})$ were from Fluka and $\mathrm{Na}_{2}{ }^{35} \mathrm{SO}_{4}$ and Sepharose CL-2B gel from Amersham Biosciences. Fractions from density-gradients were analyzed for density by weighing aliquots and absorbance at $280 \mathrm{~nm}$. Carbohydrate was detected as described previously (Nordman et al., 2002). Aliquots from radiolabelled fractions were mixed with Ready Safe (Beckman Instruments) and counted in a Wallac Guardian 1414 ßscintillation counter.

\section{Antibodies}

The 214D4monoclonal antibody, recognizing MUC1, was kindly provided by Dr J. Hilkens, Netherlands Cancer Inst. Amsterdam, The Netherlands. The LUM2-3, LUM5B-2 and LUM51 antisera, recognizing MUC2, MUC5B and MUC5AC respectively, have been described previously (Hovenberg, Davies, \& Carlstedt, 1996; Wickström, Davies, Eriksen, Veermann, \& Carlstedt, 1998). The sequences NLQYEEDMRHPG (in the repeat domain of MUC16 upstream of the binding sites for the OC 125 and M11 classes of antibodies) and RRRKKEGEYNVQQQC (in the MUC16 cytoplasmic tail) were used to raise LUM16-2 and LUM16-4 polyclonal antisera (Figure 1a). Peptides conjugated to keyhole-limpet haemocyanin (approx. $100 \mu \mathrm{g}$ ) were injected into rabbits in Freund's complete adjuvant. A booster dose of antigen in Freund's incomplete adjuvant was given after 4 weeks and the antisera collected 2 weeks later. The LUM16-2 and LUM16-4 antisera were affinity-purified against the peptide used for immunization. Working dilutions of the affinity-purified antisera are expressed relative to the original serum. 


\section{Immunohistochemistry}

Sections $(4 \mu \mathrm{m})$ of formalin fixed human tracheal tissue from a trauma victim without evidence of respiratory tract or other diseases were dewaxed, rehydrated and stained with $1 \%$ Alcian blue in 3\% acetic acid, pH 2.5 for 5 minutes at room temperature and washed with water prior to oxidation with 1\% periodic acid in 3\% acetic acid for 5 minutes followed by staining with Schiffs reagent for a further 5 minutes. Sections for immunohistochemistry were treated with $10 \mathrm{mM}$ sodium citrate buffer, $\mathrm{pH} 6$, at $100{ }^{\circ} \mathrm{C}$ for 5 min followed by $3 \%(\mathrm{v} / \mathrm{v})$ hydrogen peroxide in water for $30 \mathrm{~min}$. Non-specific binding was blocked with normal goat serum (1:5 in TBS) for $1 \mathrm{~h}$ and endogenous biotin blocked with the DAKO biotin blocking kit (Dako Cytomation, Glosterup, Denmark). Sections were then incubated with antisera M11, OC125 (diluted 1:200 in blocking solution), LUM16-2 (diluted 1:250 in blocking solution) or LUM16-2 (diluted 1:250 in blocking solution after preincubation with $10 \mu \mathrm{g} / \mathrm{ml}$ of the peptide used for immunization) for $1 \mathrm{~h}$ followed by the StreptABComplex/ HRP Duet kit (Dako Cytomation, Glosterup, Denmark) and binding visualized using diaminobenzidine (0.6 $\mathrm{mg} / \mathrm{ml}$ ) in TBS containing $0.03 \%$ (v/v) hydrogen peroxide for $15 \mathrm{~min}$. Finally, sections were counterstained with Mayer's haematoxylin.

\section{Air-liquid interface cultures}

Passage-2 normal human bronchial epithelial (NHBE) cells (strains 7821 and 9831) from Clonetics Corp. (San Diego, USA) were seeded at $1 \times 10^{5}$ cells $/ \mathrm{cm}^{2}$ onto Transwell-clear tissue culture inserts (Costar Co, Cambridge, USA) and maintained in submerged culture in bronchial epithelial growth medium (BEGM) containing transferrin $(10 \mu \mathrm{g} / \mathrm{ml})$, insulin (5 $\mathrm{g} / \mathrm{ml})$, EGF (25ng/ml), hydrocortisone $(0.5 \mu \mathrm{g} / \mathrm{ml})$, epinephrine $(0.5 \mu \mathrm{g} / \mathrm{ml})$, triidothyronine (6.5ng/ml), bovine pituitary extract (1\% v/v), amphotericin B (50ng/ml) and gentamycin (50 $\mu \mathrm{g} / \mathrm{ml}$ ) from Clonetics Corp. (San Diego, USA) until confluence. Air-liquid interface 
(ALI) cultures were obtained by removing the apical medium and replacing the basolateral one with BEGM:DMEM in a 1:1 ratio containing the same concentrations of supplements as above. All-trans RA $\left(5 \times 10^{-8} \mathrm{M}\right)$ and BSA $(1.5 \mu \mathrm{g} / \mathrm{ml})$ from Sigma Chemical Co, St Louis, USA were also added. Apical secretions were collected by applying 1ml PBS to the surface, placing the cultures at $37^{\circ} \mathrm{C}$ and aspirating gently after 10 minutes. For metabolic labelling, $50 \mu \mathrm{Ci} / \mathrm{ml} \mathrm{Na}_{2}{ }^{35} \mathrm{SO}_{4}$ was added to the medium for 24 hours and apical secretions harvested as above. For pulse-chase experiments, cells were radiolabelled for 1 hour after which the medium was replaced with “cold” ALI medium. Apical secretions were collected after the pulse (time 0 ) and 1, 2 and 4 hours of chase.

\section{Purification of mucins from the culture medium and NHBE cell layers}

Apical secretions were centrifuged (36 000rpm, 45 min, Beckman 70.1Ti rotor) to separate the gel and sol phases. An equal volume of $6 \mathrm{M} \mathrm{GdmCl,} 10 \mathrm{mM}$ sodium phosphate buffer, $\mathrm{pH}$ 6.5 containing $5 \mathrm{mM}$ sodium EDTA, $5 \mathrm{mM}$ N-ethyl maleimide, $0.1 \mathrm{mM}$ difluorophosphate (extraction buffer) was added to the sol prior to exhaustive dialysis against the same buffer at $4^{\circ} \mathrm{C}$. The gel phase was extracted three times overnight at $4^{\circ} \mathrm{C}$ in extraction buffer. Cell layers were treated with extraction buffer containing 0.1\% CHAPS. Samples (sol, gel and cell extract) were mixed with $\mathrm{CsCl}$ and $10 \mathrm{mM}$ sodium phosphate buffer, $\mathrm{pH} 6.5$ containing $5 \mathrm{mM}$ sodium EDTA to an initial density of $1.39 \mathrm{~g} / \mathrm{ml}$ and subjected to isopycnic density-gradient centrifugation (36 $000 \mathrm{rpm}, 15^{\circ} \mathrm{C}, 80$ h, 50.2 Ti rotor, Beckman Optima L-70 centrifuge).

\section{ELISA and radioimmunoprecipitation}

Samples $(100 \mu \mathrm{l})$ from density- and rate-zonal gradients and gel chromatography runs as well as appropriate positive and negative controls for the antibodies were coated onto multiwell assay plates for $18 \mathrm{~h}$ at room temperature. The plates were blocked for $1 \mathrm{~h}$ with $0.15 \mathrm{M} \mathrm{NaCl}$, 5mM sodium phosphate buffer, $\mathrm{pH} 7.4$ containing $0.05 \%$ (v/v) Tween 20 and $0.5 \%$ (w/v) 
bovine serum albumin (blocking solution) followed by $1 \mathrm{~h}$ incubation with antibodies diluted 1:2000 (LUM5-1), 1:1000 (LUM2-3, LUM5B-2), 1:250 (LUM16-2) or 1:50 (214D4) in blocking solution. All samples studied with the LUM2-3 and LUM5B-2 antisera were subjected to reduction and alkylation before analysis as described previously cells (Hovenberg, Davies, \& Carlstedt, 1996; Wickström, Davies, Eriksen, Veermann, \& Carlstedt, 1998). Reactivity was detected using an alkaline phosphatase-conjugated swine anti-rabbit serum diluted 1:2000 in blocking solution with nitrophenyl phosphate $(2 \mathrm{mg} / \mathrm{ml}$ in $5 \mathrm{mM}$ $\mathrm{MgCl}_{2}, 1 \mathrm{M}$ diethanolamine buffer, $\mathrm{pH} 9.8$ ) as a substrate. Reactivity was expressed as absorbance at $405 \mathrm{~nm}$ after $1 \mathrm{~h}$. Immunoprecipitation with the OC125 antibody was performed as described by Yin et al., 1996 and the solubilized precipitates counted in a Wallac Guardian 1414 ß-scintillation counter or subjected to agarose gel electrophoresis. Normal mouse serum was used as a control.

\section{Gel Chromatography and Rate-zonal Centrifugation}

Fractions pooled as shown in Figure 3c were run before and after reduction/alkylation on a Sepharose CL-2B column eluted with 4M GdmCl, pH 7. Fractions (1ml) were analyzed for radioactivity and reactivity with the LUM16-2, LUM5B-2 and 214D4 antibodies. For ratezonal centrifugation, samples $(100 \mu \mathrm{l})$ in $5 \mathrm{M}$ guanidinium chloride were layered onto a gradient of 6-8 M guanidinium chloride, $10 \mathrm{mM}$ sodium phosphate buffer, $\mathrm{pH} 7$ and spun in a Beckman SW-41 rotor at $40000 \mathrm{rpm}, 20^{\circ} \mathrm{C}$ for $4 \mathrm{~h}$. Fractions (300 $\left.\mu \mathrm{l}\right)$ were taken from the top of the tubes and analysed for $\left[{ }^{35}\right.$ S] sulphate and LUM16-2 or LUM5B-2 reactivity.

\section{Gel Electrophoresis and Western Blotting}

Concentrated material from the Sepharose CL-2B column (Figure 4a, pool B) was subjected to electrophoresis on a $1 \%(\mathrm{w} / \mathrm{v})$ agarose gel at $30 \mathrm{~V}$ for $16 \mathrm{~h}$ as described previously (Thornton et al., 1996). The gel was equilibrated in 60mM sodium citrate buffer, $\mathrm{pH} 7$ 
containing $0.6 \mathrm{M} \mathrm{NaCl}$, and the molecules transferred to nitrocellulose (pore size $0.45 \mu \mathrm{m}$ ) by vacuum blotting in the same buffer at $4.0 \mathrm{kPa}$ for $6 \mathrm{~h}$ with a VacuGene XL blotter (Amersham Biosciences). Membranes were then either dried and exposed to Agfa Cronex 5 film or blocked for $1 \mathrm{~h}$ with blocking solution followed by $1 \mathrm{~h}$ incubation with the 214D4 antiserum diluted 1:50 in blocking solution. Reactivity was detected using a horseradish peroxidaseconjugated goat anti-rabbit serum diluted 1:2000 in blocking solution.

Secretions from three individuals with no clinical signs of respiratory disease were collected by expectoration after rinsing of the oral cavity to reduce salivary contamination and mixed with an equal volume of $6 \mathrm{M} \mathrm{GdmCl,} 10 \mathrm{mM}$ sodium phosphate buffer, $\mathrm{pH} 6.5$ containing 5 mM sodium EDTA, 5 mM N-ethyl maleimide, $0.1 \mathrm{mM}$ difluorophosphate (extraction buffer) and stirred overnight at $4^{\circ} \mathrm{C}$. Following exhaustive dialysis against water and lyophilization, samples were resuspended in SDS loading buffer containing reducing agent according to the manufacturers instructions and $20 \mu \mathrm{g} /$ well loaded onto NuPAGE Novex 4-12\% Bis-Tris polyacrylamide gels. After electrophoresis at $200 \mathrm{~V}$ for $35 \mathrm{~min}$, molecules were electroblotted onto nitrocellulose membranes, blocked with 5\% skim milk and detected using the LUM16-2 or M11 antiserum (diluted 1:100 in 5\% skim milk) with a swine anti-rabbit HRP conjugated antiserum or a rabbit anti-mouse HRP conjugated antiserum (DakoCytomation), diluted 1:2000 in 5\% skim milk. The membranes were treated with the ECL-Western Blotting detection kit (Amersham Biosciences).

Cell layers from two independent cultures of NHBE cells were extracted at $4^{\circ} \mathrm{C}$ in RIPA buffer (150mM NaCl, 50mM Tris, 1\% NP-40, 0.5\% deoxycholic acid, 0.1\% SDS, 1mM PMSF, $1 \mathrm{mM} \mathrm{NaV}$ and 0.3 trypsin inhibitory units aprotinin). The lysates were cleared by centrifugation, dialysed against water and lyophilized. Cell extracts, or reduced/alkylated gel from secretions of two independent cell cultures (dialysed against water and lyophilized) 


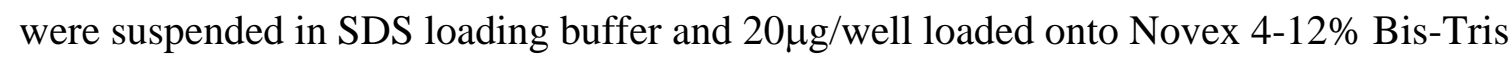
polyacrylamide gels as run as above. After electroblotting, membranes were blocked with 5\% skim milk and detected using LUM16-2 or LUM16-4 antisera (diluted 1:100 in 5\% skim milk) and binding visualized as above.

\section{Mass Spectroscopy}

Fractions ( Figure 4c, pool A) were dialyzed against water, lyophilized and digested overnight at $37^{\circ} \mathrm{C}$ with $1 \mu \mathrm{g}$ of trypsin per $10 \mu \mathrm{g}$ of protein in $100 \mathrm{mM}$ ammonium bicarbonate, $\mathrm{pH} 8.0$. Tryptic peptides were separated from high $\mathrm{M}_{\mathrm{r}}$-glycopeptides using a Sephacryl S-100 column eluted with 100 mM ammonium bicarbonate, pH 8.0 and lyophilized. Peptides were solubilized in $0.1 \%$ formic acid and separated by reverse-phase chromatography and analyzed in-line by positive ion ESI-MS-MS using a Q-ToF micro mass spectrometer (Waters, Manchester, UK). Samples were introduced via a capillary liquid chromatography system fitted with a stream select module (Waters, Manchester, UK). Aliquots (10-50 $\mu \mathrm{l})$ of the samples were separated on a Pepmap column $(0.075 \times 150 \mathrm{~mm})$ with a gradient of $5 \%$ acetonitrile in $0.1 \%$ formic acid to $25 \%$ acetonitrile in $0.1 \%$ formic acid over $30 \mathrm{~min}$ at a rate of $200 \mathrm{nl} / \mathrm{min}$. Data acquired was analyzed using SwissProt and Trembl databases with the Proteinlynx global server 1.1 software (Waters, Manchester, UK). Parameters were set to 100 milliDa peptide mass tolerance, methionine oxidation and carboxyamidomethyl cysteine modification. 


\section{RESULTS}

\section{MUC16 is produced in human tracheal secretory cells}

The LUM16-2 antiserum, raised against a sequence in the repeat domain of MUC16 (Figure 1a), was used to stain human tracheal tissue. MUC16 mucins were identified in some epithelial cells and as a layer on the luminal surface at the base of the cilia (Figure 1b). The cytoplasm of the ciliated cells showed no reactivity while heavy staining was seen over a subpopulation of cells in the submucosal glands (Figure 1c). The monoclonal CA 125/MUC16 antibodies - M11 (Figure 1d,e) and OC125 (data not shown) gave the same staining pattern as LUM16-2, verifying that the LUM16-2 antiserum does recognize MUC16. Staining with Alcian blue/PAS confirmed that MUC16 was produced by mucus-secreting cells: goblet cells in the epithelium (Figure 1f) and mucous cells in the submucosal glands (Figure 1g). Staining with the LUM16-2 was specific as shown by the complete abolition of staining after pre-incubation of the antiserum with the peptide used for immunization (Figure 1h,i).

\section{MUC16 is present in normal human respiratory tract mucus and secretions from cultured bronchial epithelial cells}

To investigate the presence of MUC16, normal human airway secretions were subjected to SDS-PAGE followed by Western blotting with the LUM16-2 or M11 antiserum (Figure 2). In the three individuals tested, both antisera stained a band which only just entered the top of the gel and is likely to correspond to the large N-terminal domain of MUC16 showing that MUC16 is a component of normal human airway secretions. The presence of MUC16 in secretions from NHBE cells was studied using density-gradient centrifugation. In both the sol and the gel phases, a carbohydrate assay identified glycosylated molecules between 1.50 and $1.43 \mathrm{~g} / \mathrm{ml}$ co-distributing with a peak of $\left[{ }^{35} \mathrm{~S}\right]$ sulphate label (Figure 3a\&c). LUM16-2 
reactivity revealed MUC16 mucins at $1.46 \mathrm{~g} / \mathrm{ml}$ coinciding with the radiolabel. A population of MUC5B mucins was found at a lower density $(1.41 \mathrm{~g} / \mathrm{ml})$ together with MUC1 mucins as visualized with the 214D4 antibody (Figure 3b\&d). The LUM5-1 and LUM2-3 antisera showed no reactivity suggesting that MUC5AC and MUC2 are not secreted by NHBE cells under these conditions. Although the amount of material was much less, mucins from the cell layer were similar to those in the gel and sol phases of the secretions with the major peak, as shown by the carbohydrate assay, at $1.46 \mathrm{~g} / \mathrm{ml}$ (Figure 3e). Absorbance at $280 \mathrm{~nm}$ was found at $1.47 \mathrm{~g} / \mathrm{ml}$ and the top of the gradient corresponding to the banding positions of DNA and proteins respectively. MUC16 was shifted towards the high-density side of the carbohydrate distribution, coinciding with the $\left[{ }^{35}\right.$ S]sulphate-label (Figure 3f). MUC5B was again the predominant oligomeric mucin with neither MUC5AC nor MUC2 present. From the relative LUM16-2 reactivities, MUC16 was approximately evenly distributed between the sol the gel suggesting that the mucins are not gel-forming. Less than 10\% of the total MUC16 was associated with the cells.

\section{Characterization of the $\left[{ }^{35}\right.$ S]sulphate labelled mucins from NHBE cells}

Gel chromatography showed that MUC16 and MUC5B, as well as some of the $\left[{ }^{35}\right.$ S $]$ sulphate from the secreted gel phase (pooled as shown in Figure 3c), were large and eluted in the void volume (Figure 4a\&b). A peak of smaller [ ${ }^{35}$ S]sulphate-labelled molecules which was included, overlapped with MUC1 mucins. To determine whether this $\left[{ }^{35}\right.$ S]sulphate was in MUC1 mucins or another molecule which co-eluted with them, the material (pooled as shown in Figure 4a, Pool B) was subjected to agarose gel electrophoresis. This showed that the major part of the radioactivity was largely separated from MUC1 suggesting the presence of two molecular species within the material - MUC1 and [ ${ }^{35}$ S $]$ sulphate-labelled molecules (Figure 4b, insert). The elution position of the radiolabelled molecules did not change after 
reduction suggesting that they are monomeric rather than oligomers joined by disulphide bonds (Figure 4c\&d). This material was not studied further. After reduction, MUC5B mucins gave rise to subunits which were partially included (Figure 4d) while LUM16-2 reactivity and the $\left[{ }^{35} \mathrm{~S}\right]$ sulphate, remained in the void (Figure 4c). This shows that the MUC5B mucins are not radiolabelled with $\left[{ }^{35}\right.$ S $]$ sulphate and also confirms that the LUM16-2 antibody does not cross-react with MUC5B. To identify whether the $\left[{ }^{35}\right.$ S $]$ sulphate label in the void volume fraction was present in the MUC16 mucins, the material was pooled as shown in Figure 4a, Pool A and subjected to immunoprecipitation with the OC125 antibody. Approximately ninety percent of the radiolabel was precipitated by the antibody but not the mouse serum control. Agarose electrophoresis showed that the radiolabel banded at the same position as the OC125 antibody reactivity indicating that the major part of the $\left[{ }^{35}\right.$ S]sulphate in this fraction is present in MUC16 mucins. To determine if $\left[{ }^{35}\right.$ S]sulphate labelled proteoglycans were also present in the void (pooled as shown in Figure 4a, Pool A) the material was digested with chondroitin ABC or heparan sulphate lyase followed by gel chromatography. No oligosaccharides resulting from degradation of glycosaminoglycan chains were seen after this treatment indicating that the material does not contain proteoglycans with chondroitin/dermatan sulphate or heparan sulphate side chains (results not shown). When the material was subjected to positive ion ESI-MS-MS after trypsin digestion, 11 peptide sequences from MUC16 were found (Table 1), thus confirming the presence of MUC16 mucins. In addition, peptides from MUC5B but not from other mucins such as MUC4, were present. Most of the peptides from MUC16 originated from the repeat region (Figure 1a) but the most C-terminal one (AQPGTTNYQR) corresponded to a unique sequence in the $\mathrm{N}$ terminal region of the most C-terminal SEA domain. Although peptides which occur only 
once in the sequence were detected, no peptides from the extended N-terminal glycosylated domain identified by O’Brien, Beard, Underwood, \& Shigemasa, (2002) were found.

To investigate the size distribution of airway MUC16 mucins, material from the void volume of the Sepharose CL-2B column was subjected to rate-zonal centrifugation. Native MUC16 mucins appeared as a broad peak suggesting that they are highly heterogeneous in size (Figure 5a). As expected the $\left[{ }^{35} \mathrm{~S}\right]$ sulphate distribution followed MUC16 (Figure 5a). The MUC16 distribution overlapped with that of MUC5B suggesting that many of the MUC16 molecules are as large as the oligomeric MUC5B mucins (Figure 5b). Reduction gave rise to MUC5B subunits which were smaller than the native molecules (Figure 5d) while MUC16 mucins migrated further into the gradient suggesting that conformational changes induced by the treatment led to an apparent increase in molecular size (Figure 5c). When the same material was subjected to trypsin digestion followed by gel chromatography, several populations of $\left[{ }^{35}\right.$ S]sulphate-labelled fragments, the largest of which remained in the void volume, were generated (Figure 6). This shows that, as expected from the predicted sequence of MUC16, large stretches of the protein core of airway MUC16 are protected from degradation by glycan chains and that the $\left[{ }^{35}\right.$ S $]$ sulphate-label is incorporated into the glycosylated regions.

\section{Cleavage of airway MUC16}

To investigate if the MUC16 apoprotein from airway secretions is cleaved close to the transmembrane domain, as has been seen for MUC1, MUC3 and MUC12, the LUM16-2 antiserum as well as the LUM16-4 (recognizing the cytoplasmic tail of MUC16 - see Figure 1a) were used to probe Western blots after SDS-PAGE of the gel phase of secretions and cell extracts from two different cultures of NHBE cells (Figure 7). In the secretions, the LUM16-2 antiserum strongly stained material corresponding to the large MUC16 N-terminal domain 
which only just entered the gel (Figure 7, lanes 1\&2). Although equal amounts of material were loaded, staining at the top of the gel was much weaker in the cell extracts (Lanes 5\&6) suggesting that this domain was enriched in the secretions. The high-molecular-mass band did not stain with the LUM16-4 antiserum showing that the C-terminal was not associated with the large repeat domain and thus that the apoprotein is cleaved between the antibody recognition sites. Reactivity with LUM16-4 was, however, seen in both the secretions and cell extracts as a major band at approximately $20 \mathrm{kDa}$ (Lanes $3 \& 4$ and $7 \& 8$ ) with staining again much weaker in the cell extract. Thus the C-terminal fragment of MUC16 containing the transmembrane domain was not enriched in the cell extract as would be expected if the Nterminal domain was shed from the cell surface leaving the C-terminal in the apical membrane.

\section{Radiolabelling and release of MUC16 from NHBE cells}

To investigate whether MUC16 mucins have similar pattern of release to that of mucin-like components identified previously, the appearance of MUC16 in secretions from NHBE cells was studied after pulse-labelling for one hour with $\left[{ }^{35}\right.$ S $]$ sulphate. To estimate the total amount of MUC16 released over the given time period, apical secretions were reduced/alkylated and chromatographed on Sepharose CL-2B. The total amount of MUC16 was then estimated as $\left[{ }^{35} \mathrm{~S}\right]$ sulphate in the void volume. Low levels of radiolabelled MUC16 were already present in the secretions after the pulse although a maximum was reached after approximately one hour of chase (i.e. two hours after the introduction of $\left[{ }^{35}\right.$ S $]$ sulphate) (Figure 8). The level declined over the following three hours. 


\section{DISCUSSION}

To verify the specificity of the LUM16-2 antiserum and to localize MUC16, immunohistochemistry in human tracheal tissue was undertaken. The staining patterns given by the LUM16-2 antiserum and the established MUC16 antisera (M11 and OC125) were identical, indicating that LUM16-2 does recognize MUC16. Due to the putative transmembrane sequence in the apoprotein, MUC16 has been regarded as a cell-associated mucin and studies in ocular tissues show MUC16 to be present on the apical surface of the corneal and conjunctival epithelia (Argueso, Spurr-Michaud, Russo, Tisdale, \& Gipson, 2003). In our study, while there was reactivity with the antisera on the airway surface, staining was seen around the cilia rather than as a distinct layer at the apex of the epithelial cells. This made it difficult to determine whether the antibody recognized MUC16 mucins in the cell membrane or secreted molecules associated with the cilia. However, the lack of staining in the cytoplasm suggests that MUC16 mucins are not synthesized by the ciliated cells and are thus unlikely to be present in the apical membrane of these cells. In contrast, MUC16 was localized to the cytoplasm of the goblet cells and the mucous cells in the submucosal glands. This finding is supported by other studies where the mucin has been identified in airway submucosal gland cells (Nouwen, Dauwe, \& De Broe, 1990), lacrimal glands (Jäger et al., 2007) and conjunctival goblet cells (Argueso, Spurr-Michaud, Russo, Tisdale, \& Gipson, 2003). In conjunctiva, MUC16 was seen in mucin packages in the goblet cells suggesting that the molecule may be co-localized in the secretory granulae with large oligomeric mucins. Whether or not these molecules are anchored in the granule membrane or represent a "secreted” form of MUC16 is not currently known. Secreted variants have been reported for other cell-associated mucins including MUC1 (Smorodinsky et al., 1996) and MUC4 (Moniaux et al., 2000) and the existence of alternatively spliced MUC16 mRNAs lacking the transmembrane domain was reported by Yin \& Lloyd (2001). Although from our 
data it cannot be ruled out that some MUC16 is tethered in the apical membrane of ciliated cells, it appears more likely that MUC16 on the airway surface is secreted from goblet and submucosal gland cells and subsequently entrapped within the ciliary layer. This idea is compatible with a recent suggestion that MUC16 is a component of the periciliary fluid (Sheehan, Kesimer, \& Pickles, 2006).

Western blotting confirmed the presence of MUC16 as a component of respiratory mucus from healthy individuals and in secretions from cultured airway epithelial cells. NHBE cell cultures, where the predominant gel-forming mucin is MUC5B (Thornton et al., 2000), were thus used for studies of the structure and properties human airway MUC16. As expected from the predicted sequence, which lacks the D-domains required for oligomerization (O’Brien et al., 2001; Yin, Dnistrian \& Lloyd, 2002), MUC16 from the cells was monomeric. Secreted MUC16 mucins were very large with the bulk of the population appearing at a position between that of "native” MUC5B and MUC5B subunits upon rate-zonal centrifugation. Assuming a similar overall conformation for the molecules, this result correlates well with the sizes predicted from the apoprotein lengths for: MUC5B subunits [5662 amino acids (Desseyn, Buisine, Porchet, Aubert, \& Laine, 1998)], MUC16 (11722 amino acids or 22152 including the N-terminal extension) and “native” MUC5B mucins comprised of two or more subunits (Thornton et al., 1999). The apparent increase in size seen after reduction of MUC16 may be explained, for instance, by the opening of cysteine loops in the MUC16 repeat domain (O’Brien et al., 2001; Yin, Dnistrian \& Lloyd, 2002). No peptides from the extended Nterminal domain of MUC16 could be identified with mass spectroscopy, and it can thus not be determined whether the domain is present in MUC16 from the airways.

To determine if MUC16 mucins are radiolabelled and thus may correspond to mucin-like molecules identified in previous studies (Somerville et al., 1992; Svitacheva, Hovenberg, \& Davies 1998; Svitacheva, \& Davies, 2001), immunoprecipitation was carried out on 
secretions from NHBE cells metabolically labelled with $\left[{ }^{35}\right.$ S $]$ sulphate. Almost all of the highmolecular-mass, radiolabelled material was precipitated using the OC125 antibody, showing that MUC16 mucins do incorporate the radiolabel. The absence of $\left[{ }^{35}\right.$ S $]$ sulphate-labelled proteoglyans and the lack of peptide fragments from mucins other than MUC5B (which is not radiolabelled) in the excluded material as well as the complete coincidence between MUC16 and $\left[{ }^{35} \mathrm{~S}\right]$ sulphate in the rate-zonal assay, all suggest that MUC16 is the predominant $\left[{ }^{35} \mathrm{~S}\right]$ sulphate labelled molecule in the void volume of the Sepharose CL-2B column. The generation of very large glycopeptides upon trypsin digestion is similar to the breakdown pattern seen for mucin-like molecules in previous studies and consistent with the predicted structure for ovarian MUC16 as well as the results of a biochemical investigation of CA125 from an ovarian cancer cell-line (Lloyd \& Yin, 2001). In the NHBE cells, the time taken for $\left[{ }^{35} \mathrm{~S}\right]$ sulphate-labelled MUC16 molecules to reach a maximum in the secretions after the start of radiolabelling was two hours. This is similar to the time observed previously for the appearance of $\left[{ }^{35} \mathrm{~S}\right]$ sulphate-labelled mucin-like components in the medium from human airway tissue and bovine epithelial cells in culture and also agrees with the results obtained for MUC16 from OVCAR cells (Lloyd \& Yin, 2001). These data thus show that the highmolecular-mass, high-buoyant density mucin-like molecules secreted from human and bovine airway cells and tissues (Somerville et al., 1992; Svitacheva, Hovenberg, \& Davies 1998; Svitacheva, \& Davies, 2001) do correspond to MUC16, although other lower-molecular-mass molecules are also radiolabelled.

While both were present in secretions and the cell layer, the C-terminal MUC16 fragment of MUC16 was not covalently linked to the large N-terminal domain demonstrating that the apoprotein has undergone proteolysis between these regions. MUC16 has a SEA module in the C-terminal domain (O’Brien et al., 2001) and in MUC1, MUC3, MUC13, this module 
contains a conserved sequence (GSVVV) where each of these mucins may be cleaved (Palmai-Pallag et al., 2005) - with MUC1 undergoing an autocatalytic cleavage (Levitin et al., 2005). In secreted MUC16 the most C-terminal peptide identified with mass spectroscopy was a unique peptide found at the N-terminal end of this SEA domain. The C-terminal fragment has a size (20KDa) which, allowing for potential glycosylation, would be consistent with the intracellular, putative transmembrane and extracellular domains up to a position around the centre of the C-terminal domain. These data thus point to a cleavage in the Cterminal domain of MUC16, possibly in SEA module. In MUC1, the two subunits reassociate after cleavage via non-covalent interactions between sequences in the SEA domain and the molecule exists as a heterodimer (Wreschner et al., 2002). Due to the use of chaotrophic solvents during the isolation procedure, it was not possible to determine whether the C- and N-terminal domains of MUC16 re-associate in this way. The cellular location of MUC16, as well as the presence of the C-terminal fragment in secretions, suggest that the mechanism of MUC16 release may be different from that of other membrane-bound mucins e.g. MUC1, where the N-terminal domain is shed from the cell surface leaving the C-terminal in the membrane (Thathiah, Blobel, \& Carson, 2003). Cryofixation studies have indicated that secretion from goblet cells may, in part, occur via an apocrine mechanism involving discharge of whole secretory granules (Puchelle, Beorcia, Ménager, Zahm, \& Ploton, 1991). Thus, if MUC16 was anchored as a cleaved heterodimer in the membrane of the secretory granules rather than in the cell membrane, the release of whole granulae into secretions could explain our observations. However, further studies are required to determine whether or not this is the case.

In conclusion, our metabolic studies show that MUC16 is radiolabelled with [ $\left.{ }^{35} \mathrm{~S}\right]$ sulphate in NHBE cells in culture and we therefore conclude that MUC16 does correspond to one of the mucin-like molecules identified previously from airway secretions. The enhanced secretion of 
the mucin-like molecules seen previously in response to bacterial exoproducts suggests that MUC16 may play an important role in defence against bacteria on the airway surface.

\section{ACKNOWLEDGMENTS}

We thank Annika Böök for excellent technical help and Dr David Knight for interpretation of the MS data. This work was supported by the Medical Faculty of Lund; The Swedish Animal Welfare Agency; Council for Medical Tobacco Research, Swedish Match; Swedish Fund for Research without Animal Experiments; The Swedish Medical Research Council (grant 07902); The Wellcome Trust; The Knowledge Foundation (Biofilms - Research Center for Biological Interfaces), Alfred Österlunds, Crafoordska and Greta and Johan Kocks Stiftelser. 


\section{REFERENCES}

Argueso, P., Spurr-Michaud, S., Russo, C., Tisdale, A., \& Gipson, I.K. (2003). MUC16 mucin is expressed by the human ocular surface epithelia and carries the H185 carbohydrate epitope. Investigative Ophthalmology and Visual Science, 44, 2487-2495.

Bast, R.C., Feeney, M., Lazarus, H., Nadler, L.M., Colvin, R.C., \& Knapp, R.C. (1981). Reactivity of a monoclonal antibody with human ovarian carcinoma. Journal of Clinical Investigation, 68, 1331-1337.

Desseyn, J.-L., Buisine, M.-P., Porchet, N., Aubert, J.-P., \& Laine, A. (1998). Genomic organization of the human mucin gene MUC5B. cDNA and genomic sequences upstream of the large central exon. The Journal of Biological Chemistry 273, 30157-30164.

Hovenberg, H.W., Davies, J.R., \& Carlstedt, I. (1996). Different mucins are produced by the surface epithelium and the submucosa in human trachea: identification of MUC5AC as a major mucin from the goblet cells. Biochemical Journal, 318, 319-324.

Jäger, K., Wu, G., Sel, S., Garreis, F., Bräuer, L. \& Paulsen, F.P. (2007). MUC16 in the lacrimal apparatus. Histochemistry and Cell Biology 127, 433-438.

Khatri, I.A., Wang, R., \& Forstner, J.F. (2003). SEA (sea urchin sperm protein, enterokinase and agrin) - module cleavage, association of fragments and membrane targeting of rat intestinal mucin Muc3. Biochemical Journal, 372, 263-270.

Levitin, F., Stern, O., Weiss, M., Gil-Henn, C., Ziv, R., Prokocimer, Z., Smorodinsky, N.I., Rubinstein, D.B., \& Wreschner, D.H. (2005). The MUC1 SEA module is a self-cleaving domain. The Journal of Biological Chemistry 280, 33374-33386.

Lloyd, K.O., \& Yin, B.W.T. (2001). Synthesis and secretion of the ovarian cancer antigen CA 125 by the human cancer cell line NIH:OVCAR-3. Tumor Biology 22, 77-82.

Moniaux, N., Escande, F., Batra, S.K., Porchet, N., Laine, A., \& Aubert, J.P. (2000). Alternative splicing generates a family of putative secreted and membrane-associated MUC4 mucins. European Journal of Biochemistry 267, 4536-4544. 
Nordman, H., Davies, J.R., Lindell, G., de Bolos, C., Real, F., \& Carlstedt, I. (2002). Gastric MUC5AC and MUC6 are large oligomeric mucins that differ in size, glycosylation and tissue distribution. Biochemical Journal 364, 191-200.

Nouwen, E.J., Dauwe, S., \& De Broe, M.E. (1990). Occurrence of the mucinous differentiation antigen CA125 in genital tract and conductive airway epithelia of diverse mammalian species (rabbit, dog and monkey). Differentiation 45, 192-198.

Nustad, K., Lebedin, Y., Lloyd, K.O., Shigemasa, K., de Bruijn, H.W.A., Jansson, B., Nilsson, O., Olsen, K.H., \& O’Brien, T.J. (2002). Epitopes on CA 125 from cervical mucus and ascites fluid and characterization of six new antibodies. Tumor Biology, 23, 303-314.

O’Brien, T.J., Beard, J.B., Underwood, L.J., Dennis, R.A., Santin, A.D., \& York, L. (2001). The CA 125 gene: An extracellular superstructure dominated by repeat sequences. Tumor Biology, 22, 348-366.

O’Brien, T.J., Beard, J.B., Underwood, L.J., \& Shigemasa, K. (2002). The CA125 gene: A newly discovered extension of the glycosylated $\mathrm{N}$-terminal domain doubles the size of this extracellular superstructure. Tumor Biology, 23, 154-169.

Palmai-Pallag, T., Khodabukus, N., Kinarsky, L., Leir, S.-H., Sherman, S., Hollingworth, M.A. \& Harris, A. (2005). The role of the SEA (sea urchin sperm protein, enterokinase and agrin) module in cleavage of membrane-tethered mucins. Federation of European Biochemical Societies Journal, 272, 2901-2911.

Parry, S., Silverman, H.S., McDermott, K., Willis, A., Hollingsworth, M.A., \& Harris, A. (2001). Identification of MUC1 proteolytic cleavage sites in vivo. Biochemical Biophysical Research Communications, 283, 715-720.

Puchelle, E., Beorcia, A., Ménager, M., Zahm, J.-.M., \& Ploton, D. (1991). Threedimensional imaging of the mucus secretory process in the cryofixed frog respiratory epithelium. Biological Chemistry 72, 159-166.

Sheehan, J.K., Kesimer, M., \& Pickles, R. (2006). Innate immunity and mucus structure and function. In innate immunity in pulmonary infection. Novartis Foundation Symposium 279, pp157-169, Wiley Chichester. 
Smorodinsky, N., Weiss, M., Hartmann, M.L., Baruch, A., Harness, E., Yaakobovitz, M., Keydar, I., \& Wreschner, D.H. (1996). Detection of a secreted MUC1/SEC protein by MUC1 isoform specific monoclonal antibodies. Biochemical and Biophysical Research Communications, 228, 115-121.

Somerville, M., Taylor, G.W., Watson, D., Rendell, N.B., Rutman, A., Todd, H., Davies, J.R., Wilson, R., Cole, P., \& Richardson, P.S. (1992). Release of mucus glycoconjugates by Pseudomonas aeruginosa rhamnolipids into feline trachea in vivo and human bronchus in vitro. American Journal of Respiratory Cell and Molecular Biology, 6, 116-122.

Svitacheva, N., Hovenberg, H.W., \& Davies, J.R. (1998). Biosynthesis of mucins in bovine trachea: identification of the major radiolabelled species. Biochemical Journal, 333, 449-456.

Svitacheva, N., \& Davies, J.R. (2001). Mucin biosynthesis and secretion in tracheal epithelial cells in primary culture. Biochemical Journal, 353, 23-32.

Thathiah, A., Blobel, C.P., \& Carson, D.D. (2003). Tumor necrosis factor-alpha converting enzyme/ADAM 17 mediates MUC1 shedding. The Journal of Biological Chemistry, 267, 6171-6177.

Thornton, D.J., Carlstedt, I., Howard, M., Devine, P.L., Price, M.R., \& Sheehan, J.K. (1996). Respiratory mucins: identification of core proteins. Biochemical Journal 316, 967-975.

Thornton, D.J., Khan, N., Mehrotra, R., Howard, M., Veermann, E., Packer, N.H., \& Sheehan, J.K. (1999). Salivary mucin MG1 is comprised almost entirely of different glycosylated forms of the MUC5B gene product. Glycobiology, 9, 293-302.

Thornton, D.J., Grey, T., Nettesheim, P., Howard, M., Koo, J.S., \& Sheehan, J.K. (2000). Characterization of mucins from cultured normal human tracheobronchial epithelial cells. American Journal of Physiology: Lung Cellular and Molecular Physiology. 278, L11181128.

Wickström, C., Davies, J.R., Eriksen, G.K., Veermann, E., \& Carlstedt, I. (1998). MUC5B is a major gel-forming, oligomeric mucin from human salivary gland, respiratory tract and endocervix: identification of glycoforms and C-terminal cleavage. Biochemical Journal, 334, 685-693. 
Wreschner, D.H., McGuckin, M.A., Williams, S.J., Baruch, A., Yoeli, M., Ziv, R., Okun, L., Zaretsky, J., Smorodinsky, N.I., Keydar, I., Neophytou, P., Stacey, M., Linn, H.H., \& Gordon. S, (2002). Generation of ligand-receptor alliances by "SEA" module-mediated cleavage of membrane-associated mucin proteins. Protein Science, 11, 698-706.

Yin, B.W., Finstad, C.L., Kitamura, K., Federici, M.G., Welshinger, M., Kudryashov, V., Hoskins, W.J., Welt, S., \& Lloyd, K.O. (1996). Serological and immunological analysis of Lewis y (Ley) blood group antigen expression in epithelial ovarian cancer. International Journal of Cancer, 8, 406-412.

Yin, B.W., \& Lloyd, K.O. (2001). Molecular cloning of the CA125 ovarian cancer antigen: identification as a new mucin, MUC16. Journal of Biological Chemistry, 276, 27371-27375.

Yin, B.W., Dnistrian, A., \& Lloyd, K.O. (2002). Ovarian cancer antigen CA125 is encoded by the MUC16 mucin gene. International Journal of Cancer, 98, 737-740. 


\section{FIGURE LEGENDS}

Figure 1. Schematic diagram of the MUC16 molecule (a) and representative images of immunohistochemical staining of (b,d, f, h) the surface epithelium and (c,e,g,i) the submucosal glands of human tracheal tissue with (b,c) the LUM16-2 antiserum (d,e) the M11 antiserum (f,g) Alcian blue, pH 2.5/PAS and (h,i) the LUM16-2 antiserum with $1 \mu \mathrm{g} / \mathrm{ml}$ of the peptide used for immunization.

The structure of the MUC16 molecule (a) showing the N-terminal domain (W), repeat domain (ㅁ), unique sequence (圈), putative transmembrane domain ( and cytoplasmic domain ( The location of the peptides used to raise the LUM16-2 and LUM16-4 antisera are marked with arrows. The positions of the most N-terminal $(\boldsymbol{\nabla})$ and most C-terminal (*) peptides identified with mass-spectroscopy as well as the C-terminal SEA domain are indicated. At least ten sections $(4 \mu \mathrm{m})$ of human tracheal tissue were stained with either (b\&c) the LUM16-2 antiserum, (d\&e) the M11 monoclonal antibody or (h,i) the LUM16-2 antiserum with $1 \mu \mathrm{g} / \mathrm{ml}$ of the immunizing peptide, visualized with DAB (brown) and counterstained with Mayers haematoxylin. For identification of mucus-secreting cells, tissue sections were also stained with Alcian blue/PAS. The positions of goblet cells (b,d,f,h) or submucosal gland mucous cells (c,e,g,i) are marked with arrows. The scale bar represents $50 \mu \mathrm{m}$.

Figure 2. SDS-PAGE and Western blotting of respiratory tract secretions from three healthy individuals

Reduced/alkylated secretions from three individuals (lanes 1 \& 4), (lanes 2 \& 5) and (lanes 3 \& 6) were subjected to SDS-PAGE gel electrophoresis and Western blotting as described in the text. Membranes were stained for reactivity with the M11 (lanes 1-3) or LUM16-2 (lanes 4-6) antiserum. 
Figure 3. Isopycnic density-gradient centrifugation of secretions and cell extract from NHBE cells

The sol (a,b) and the gel phase (c,d) of apical washings as well as the GdmCl soluble cell extract (e,f) from NHBE cells radiolabelled with [ ${ }^{35}$ S]sulphate for 24 hours were subjected to density-gradient centrifugation in a Beckman Optima centrifuge (36 $000 \mathrm{rev} . / \mathrm{min}, 15^{\circ} \mathrm{C}$, approx. 80 h, Beckman 50.2 Ti rotor) in CsCl, 4M GdmCl (starting density 1.39 g/ml).

Fractions were analyzed for (a,c,e); density ( $\mathbf{\square})$, carbohydrate (o), $\left[{ }^{35}\right.$ S $]$ sulphate $(\triangle)$ and $A_{280}$

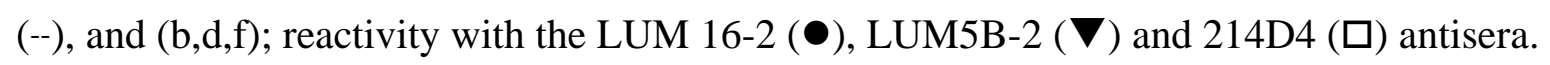

\section{Figure 4. Gel chromatography of the gel phase of secretions from NHBE cells}

Samples pooled as shown in Figure 3c were chromatographed on a Sepharose CL-2B column eluted at $0.1 \mathrm{ml} / \mathrm{min}$ with $4 \mathrm{M} \mathrm{GdmCl}, \mathrm{pH} 7$ before $(\mathrm{a}, \mathrm{b})$ or after (c\&d) reduction. Fractions were analyzed for $(\mathrm{a}, \mathrm{c})\left[{ }^{35}\right.$ S $]$ sulphate $(\triangle)$ and reactivity with the LUM16-2 $(\bullet)$ antiserum and (b,d) reactivity with the LUM5B-2 ( $\boldsymbol{\nabla})$ or 214D4 ( $\square$ ) antiserum. $\mathrm{V}_{0}-$ void volume, $\mathrm{V}_{\mathrm{T}}-$ total volume. Figure 4a (insert) - Material from Pool A (Figure 3a) was immunoprecipitated with the OC125 antibody and the precipitate subjected to agarose gel electrophoresis and Western blotting. Membranes were analysed for: lane 1 - radioactivity and lane 2 - reactivity with the LUM16-2 antiserum. Figure 4b (insert) - Material from Pool B (Figure 3a) was subjected to agarose gel electrophoresis and Western blotting. Membranes were analysed for: lane 1 - radioactivity and lane 2 - reactivity with the 214D4 monoclonal antibody.

Figure 5. Rate-zonal centrifugation of (a,b) 'native' and (c,d) reduced mucins from the void volume of Sepharose CL-2B 
Material from the void volume of a Sepharose CL-2B column (Figure 3a, Pool A) was subjected to rate-zonal centrifugation before and after reduction/alkylation as described in the text. Fractions were analysed for: $(\mathrm{a} \& \mathrm{c})\left[{ }^{35}\right.$ S $]$ sulphate $(\triangle)$, reactivity with the LUM16-2 $(\bullet)$ antiserum and (b\&d) reactivity with the LUM5B-2 ( $\boldsymbol{\nabla})$ antiserum.

\section{Figure 6. Gel chromatography of $\left[{ }^{35}\right.$ S]sulphate-labelled MUC16 after trypsin digestion} Void volume fractions from 'native' secretions (Figure 3a, Pool A) were digested with trypsin and chromatographed on a Sepharose CL-2B column in 4M GdmCl, $\mathrm{pH} 7$ as described in the text. Fractions were analyzed for $\left[{ }^{35} \mathrm{~S}\right]$ sulphate $(\triangle) . \mathrm{V}_{0}$ - void volume, $\mathrm{V}_{\mathrm{T}}$ - total volume.

Figure 7. SDS-PAGE of apical secretions (lanes 1-4) and cell extract (lanes 5-8) from culture 1 (lanes 1,3,5,7) and culture 2 (lanes 2,4,6,8) of NHBE cells Reduced/alkylated gel from apical secretions and reduced/akylated cell extract from 2 independent cultures of NHBE cells were subjected to SDS-PAGE gel electrophoresis and Western blotting as described in the text. Equal amounts of protein were loaded into each of the wells. Membranes were stained for: lanes 1,2,5\&6 - reactivity with the LUM16-2 antiserum or lanes 3,4,7\&8 - reactivity with the LUM16-4 antiserum.

Figure 8. Time-course for the release of $\left[{ }^{35}\right.$ S]sulphate-labelled MUC16 into secretions from NHBE cells in culture

NHBE cells were pulse-labelled for 1 hour and the amount of $\left[{ }^{35}\right.$ S $]$ sulphate-labelled MUC16 in the secretions at subsequent time points was estimated as described in the text. The amounts are shown as output/hr against time $(\triangle)$ 
Peptide

DGAATGVDAICTHR

DSLYVNGFTHR

NSLYVNGFTHR

STSVGPLYSGCR

AQPGTTNYQR

LDPLNPGLDR

ELGPYTLDR

VDPIGPGLDR

LTLLRPEK

LASLRPEK

VLQGLLR

*Sequence Q96RK2 from TrEMBL.

\section{Position in MUC 16 sequence*}

3998-4011, 4312-4325, 4469-4482

5297-5307, 6388-6398

3890-3900, 4204-4214, 4673-4683, 4829-4839

5229-5240, 5385-5396, 5697-5708, 6165-6176

6827-6836

$5419-5428$

4195-4203, 4351-4359, 4508-4516, 4664-4672,

$4820-4828$

5107-5116

3990-3997, 4617-4624, 5085-5092, 5241-5248,

5397-5404, 5553-5560, 5709-5716, 5865-5872,

6177-6184, 6332-6339

3834-3841

6154-6160 


\section{Table 1 Peptides identified by ESI-MS-MS analysis}

Gel phase from apical secretions from NHBE cells was subjected to density-gradient centrifugation, reduced and alkylated and chromatographed on a Sepharose CL-2B column. The void volume fractions (pooled as shown in Figure 3c - pool A) were digested with trypsin and subjected to ESI-MS-MS analysis. The parent and fragment ion masses were within 50 mDa of the theoretical values. The locations of the most N-terminal and C-terminal peptides generated are shown in Figure 1a. 
(a)

C-terminal SEA domain
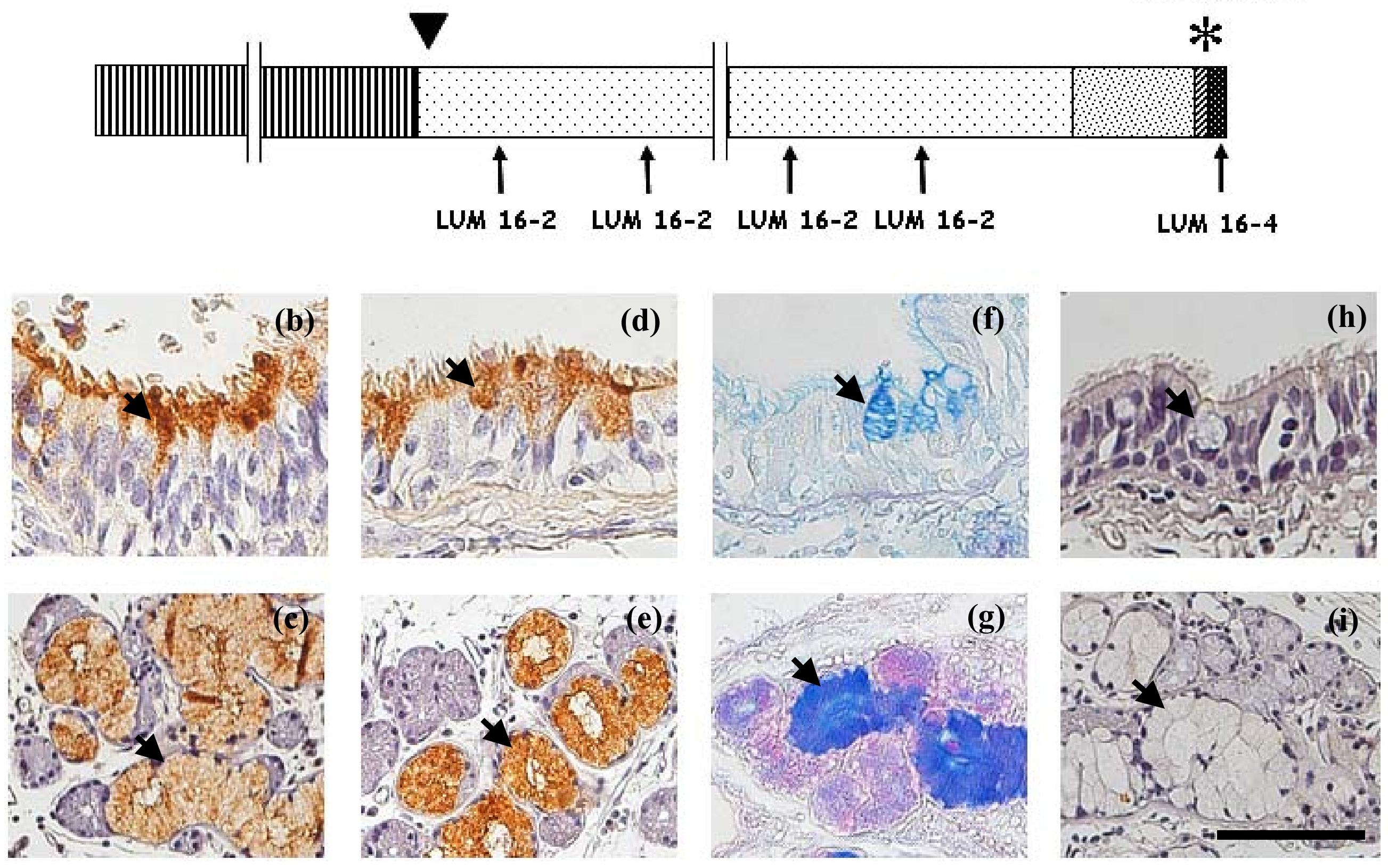


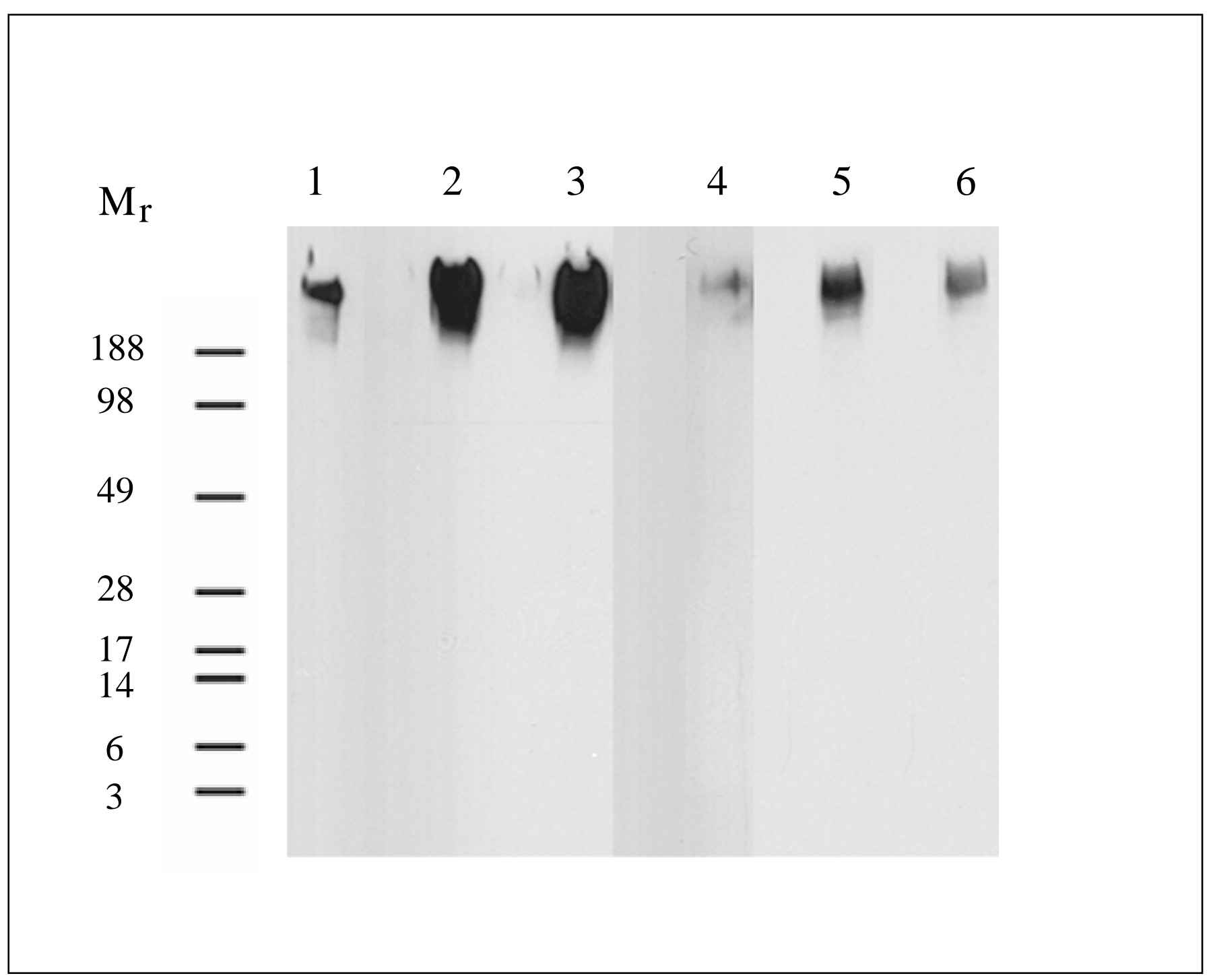




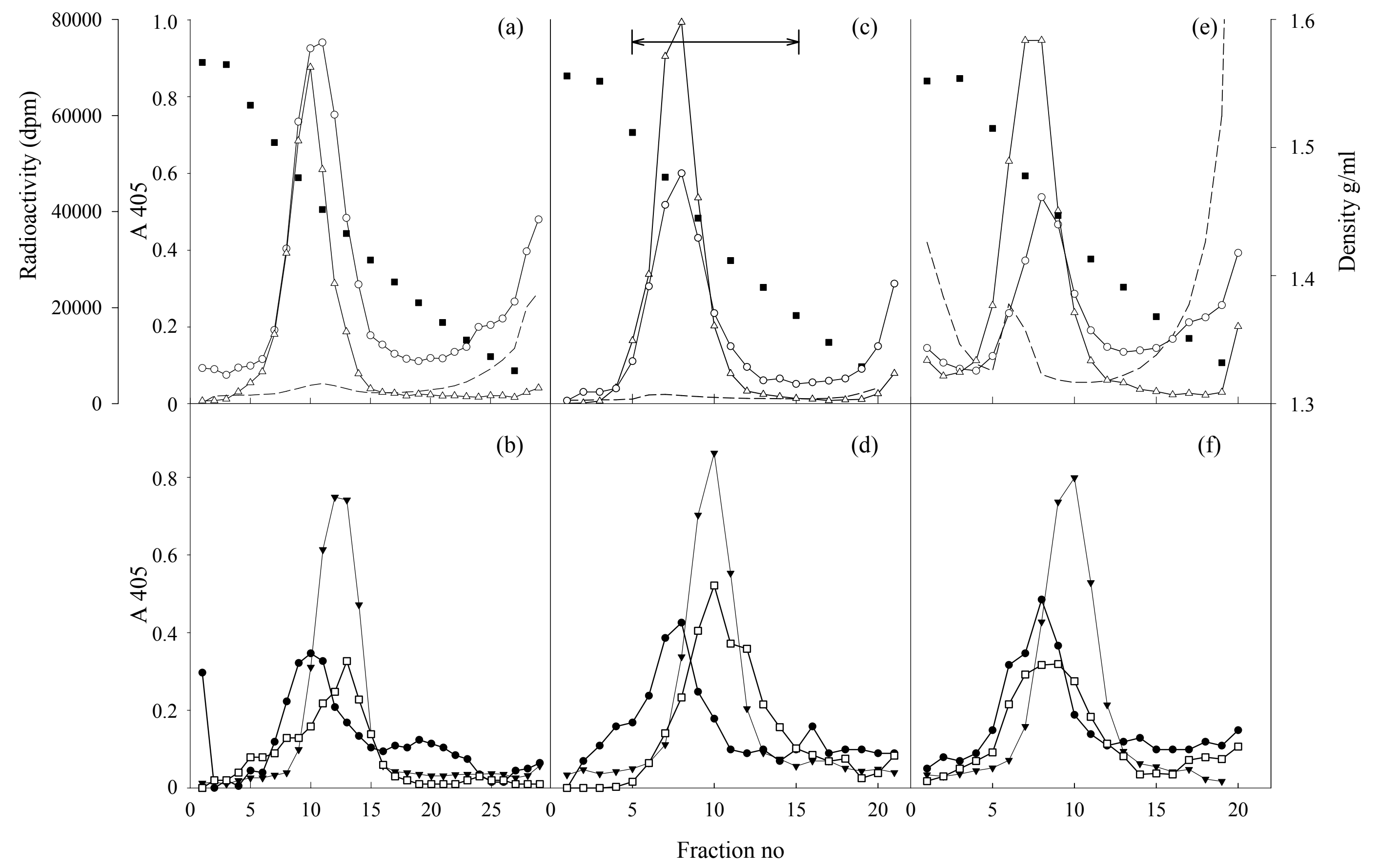




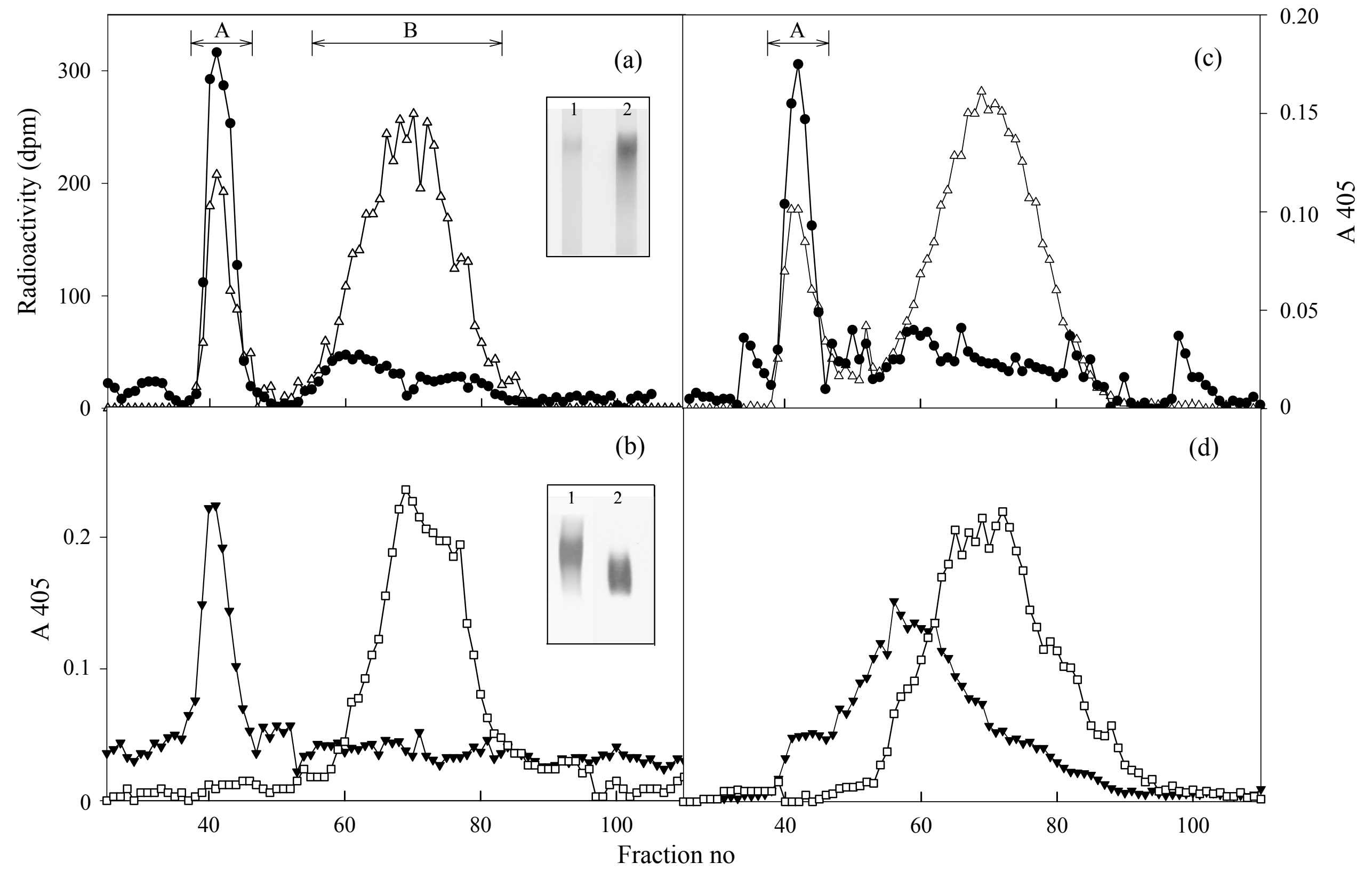




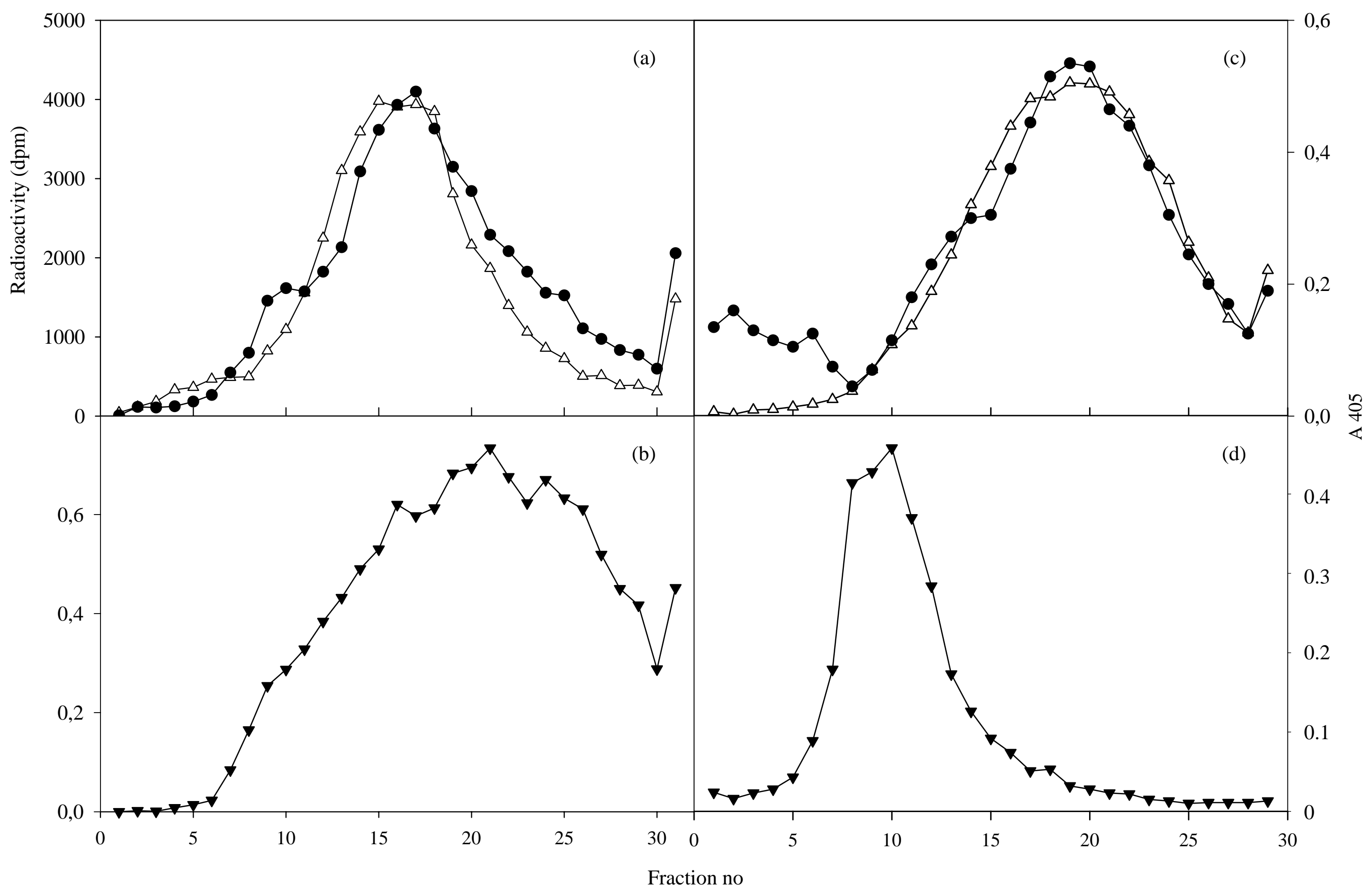




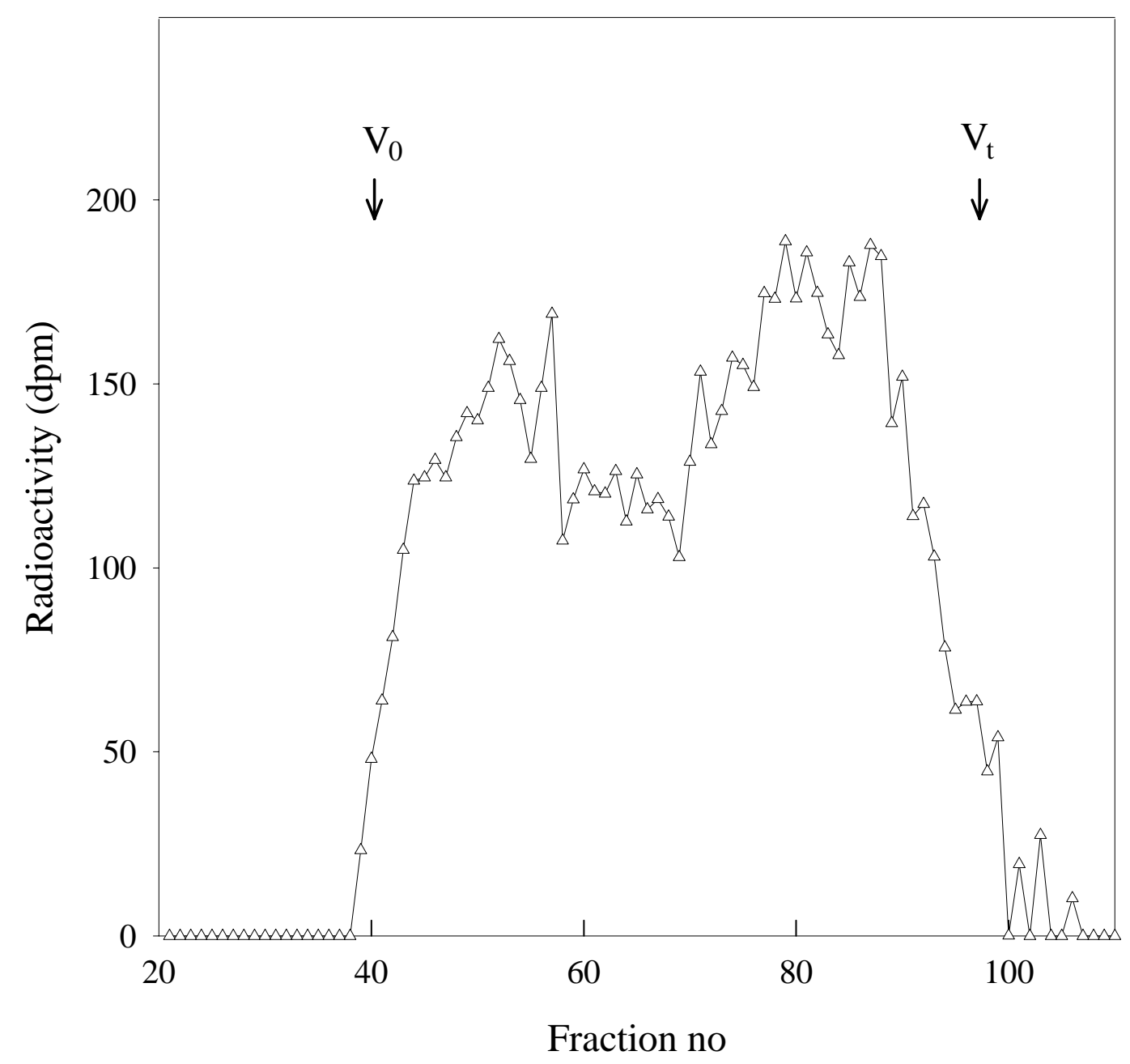




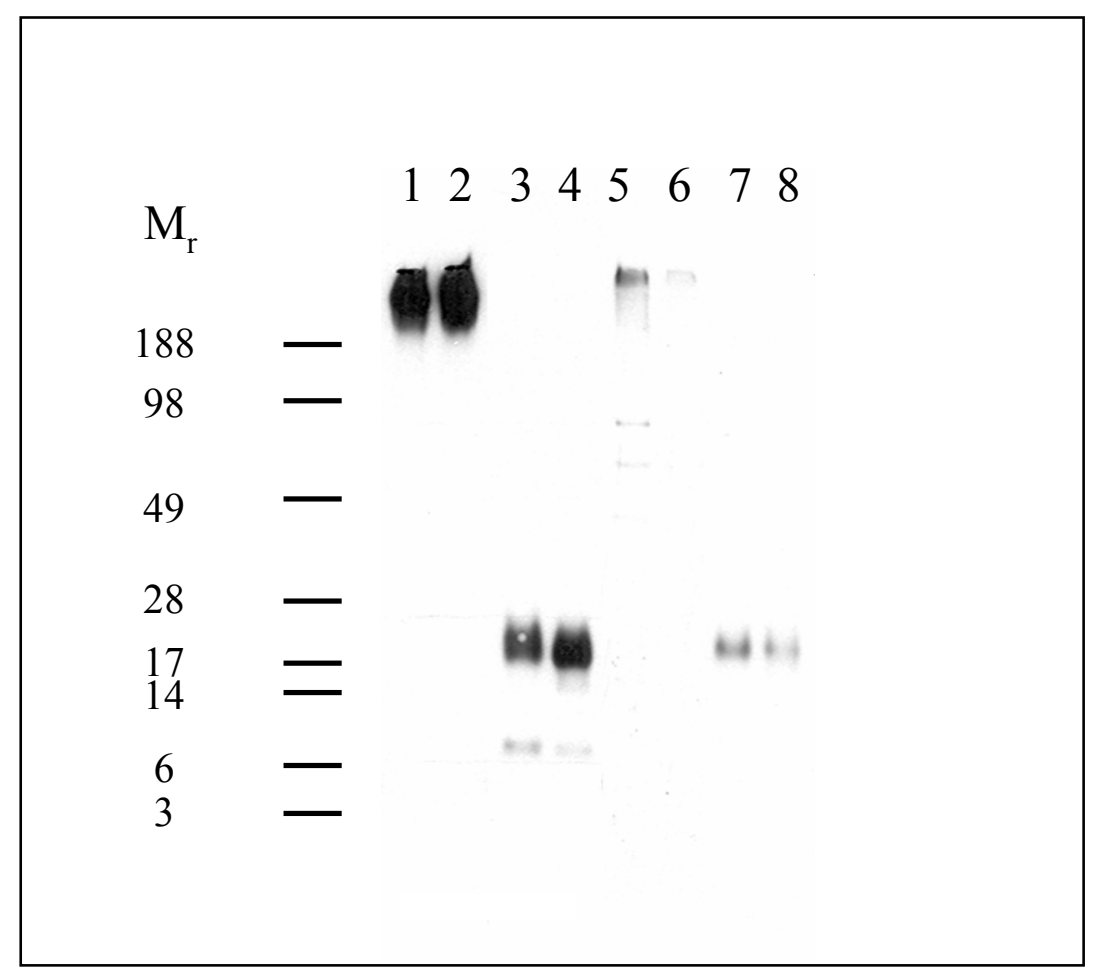




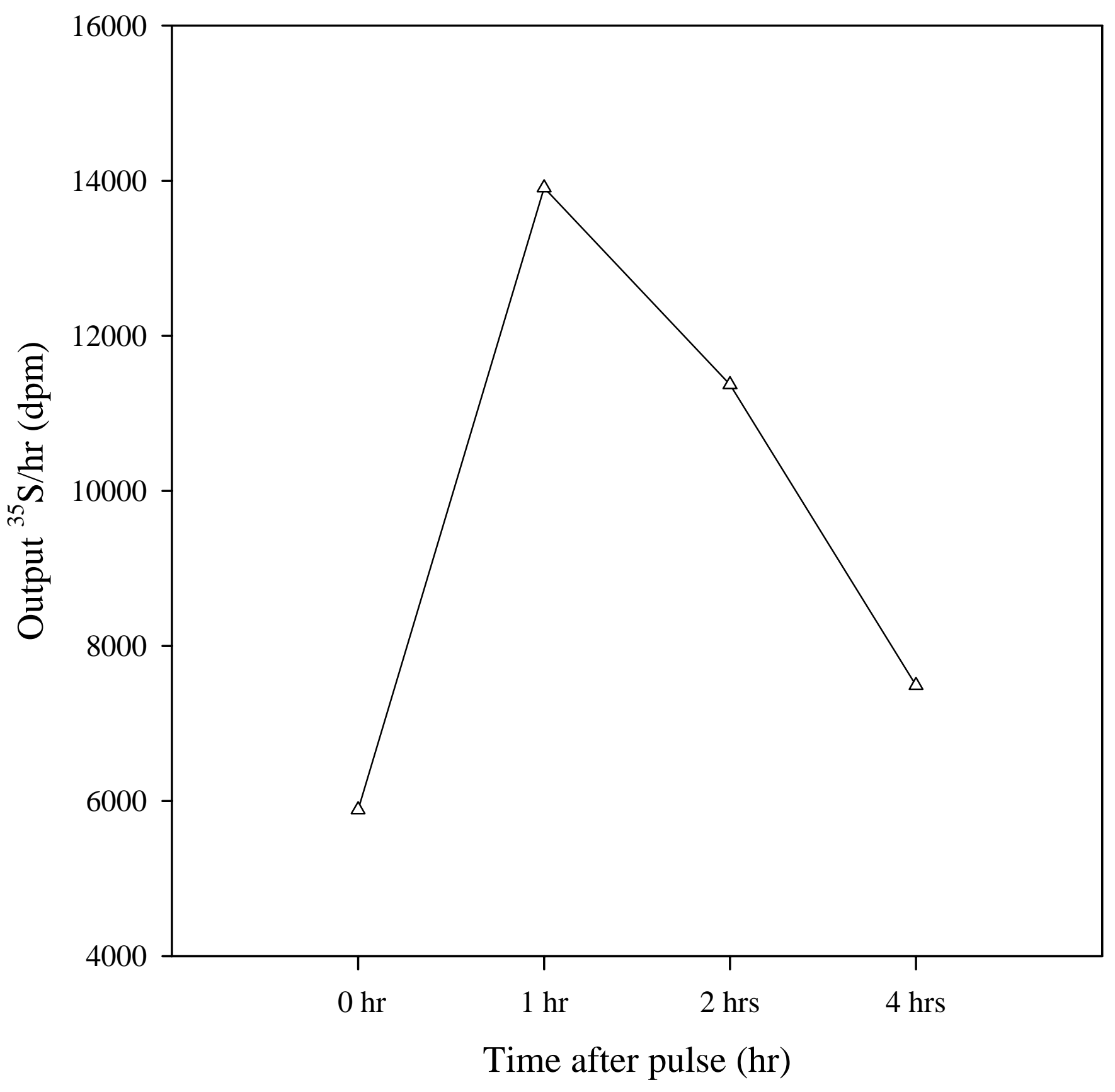

